\title{
Year-round passive acoustic data reveal spatio- temporal patterns in marine mammal community composition in the Weddell Sea, Antarctica
}

\author{
I. Van Opzeeland ${ }^{1,2, *}$, H. Hillebrand ${ }^{2,3}$ \\ ${ }^{1}$ Ocean Acoustics Lab, Alfred-Wegener Institute (AWI), Helmholtz Centre for Polar and Marine Research, \\ 27570 Bremerhaven, Germany \\ ${ }^{2}$ Helmholtz Institute for Functional Marine Biodiversity (HIFMB), Carl von Ossietzky University, Oldenburg, \\ 26129 Oldenburg, Germany \\ ${ }^{3}$ Plankton Ecology Lab, Institute for Chemistry and Biology of the Marine Environment (ICBM), \\ Carl von Ossietzky University Oldenburg, 26382 Wilhelmshaven, Germany
}

\begin{abstract}
To date, the majority of studies investigating marine mammal distribution and behavior take a single-species perspective, which is often driven by the logistic difficulties of collecting appropriate data at sea. Passive acoustic monitoring, provided recording tools exhibit sufficient bandwidth, has the potential to provide insights into community structure as devices operate autonomously simultaneously collecting data on baleen, pinniped and toothed whale acoustic presence. Data can provide information on local species diversity, residency times and co-occurrence. Here, we used multi-year passive acoustic data from 6 sites in the Weddell Sea, Southern Ocean, to explore how local marine mammal community compositions develop over time and in relation to sea-ice. Diversity peaked in austral late spring and early summer, shortly before seasonal sea-ice break-up. The effective number of species exhibited little variation over time, reflecting that species remain in Antarctic waters throughout austral winter. Community composition showed almost complete seasonal overturn, indicating that species replace each other throughout the year. For all 6 sites, community dissimilarity increased with increasing temporal distance, reflecting temporal trends in community composition beyond seasonality. Several species exhibited significant positive or negative co-occurrence patterns over time. These seasonal associations were consistent across all 5 oceanic sites, but partly inversed at the Western Antarctic Peninsula recording site. This study shows that the application of biodiversity metrics to passive acoustic monitoring data can foster insights into the timing of behaviors and community composition, which can boost the interpretation of responses in the light of ongoing environmental changes.
\end{abstract}

KEY WORDS: Biodiversity change - Species composition · Richness · Passive acoustic monitoring · Marine mammals $\cdot$ Southern Ocean

\section{INTRODUCTION}

In many regions of the world, inventory studies aiming to understand the role and functioning of community composition are facing a race against the clock as direct and indirect effects of human-induced

${ }^{*}$ Corresponding author: ilse.van.opzeeland@awi.de global changes are causing rapid and extreme shifts in animal and plant communities across ecosystems (Sala et al. 2000, Lotze et al. 2006, Sorte et al. 2017). In the marine realm, ecosystems are experiencing a multitude of human pressures, comprising chemical pollution, climate-induced changes (e.g. sea-level

(C) The authors 2020. Open Access under Creative Commons by Attribution Licence. Use, distribution and reproduction are unrestricted. Authors and original publication must be credited. 
rise, ocean acidification, sea-ice melt), fishing, marine debris and increasing underwater noise levels (Halpern et al. 2015). In many marine regions, these stressors have or are expected to have severe consequences for ecosystem health and biodiversity (Worm et al. 2006, Hillebrand et al. 2018a). Assessing patterns of richness and composition of marine animal communities through ecological gradients such as latitude and depth and over time are of primary importance in conservation biology as these can provide important warning signs of environmental change for management and conservation measures to respond to. Fast and reliable methods are required for biodiversity assessments to determine and compare species richness patterns that can be applied in both accessible and remote habitats.

Rapid acoustic surveys, relying on acoustic analyses of sound produced by animal communities, have proved a fast, reliable and non-invasive method to collect information on biological diversity in terrestrial realms (Sueur et al. 2008, Andreassen et al. 2014, Darras et al. 2017). In marine environments, passive acoustic methods have become an established method to acquire information on the occurrence and behaviour of sound-producing species (e.g. Van Parijs et al. 2009). In contrast to visual sightings, passive acoustic data collection in marine underwater environments can occur with autonomous recording units that are relatively independent of weather and light conditions, securing data acquisition on a year-round basis. For polar environments, the collection of passive acoustic data offers the most reliable tool of choice to obtain year-round information on species distribution (e.g. Van Opzeeland et al. 2008, 2013b, Van Parijs et al. 2009). Visual sighting data on marine mammals in polar waters are seasonally biased to the summer period as the access of ships is often too restricted to carry out surveys during winter due to adverse weather and light conditions and heavy ice cover in large areas. Autonomously operating acoustic recording devices are deployed year-round throughout the world's oceans and, provided sufficient recording bandwidth, have the potential to provide a wealth of information relating to acoustic communities and local species compositions. To date, however, most marine passive acoustic studies have taken a single-species perspective (most often marine mammals), only rarely consolidating contextual acoustic data in analyses and interpretation providing information on acoustic environments, biodiversity or species association patterns (for a review, see Risch \& Parks 2017, also see Roca \& Van Opzeeland 2019).
Marine mammals dominate large parts of the natural acoustic environment in most polar waters and their sounds are generally well known, in contrast to many fishes, crustaceans and invertebrates for which information on acoustic behavior is much sparser, if existent at all. Due to the fact that marine mammals are often migratory, apex predators, exhibiting long life spans, they integrate ecological variation across large spatial and temporal scales and have been described as sentinels of various marine ecosystems (e.g. Aguirre \& Tabor 2004, Moore \& Huntington 2008). Monitoring of sentinel species can play an important role in detecting first warning signals and understanding the effects of environmental change for impacted regions (Moore 2008). In contrast to physical measurements of the environment, sentinel species, particularly when studied as part of a(n acoustic) community, can allow assessment of the integrated response of organisms to environmental pertubations (Milnes \& Guillette 2008, Templeton et al. 2016).

Here, we used multi-year passive acoustic recordings from 6 sites throughout the Antarctic Weddell Sea, comprising data on acoustic presence from 9 marine mammal species, of which some exhibit migratory behavior (e.g. fin and Antarctic blue whales) and some are resident species of which at least part of the population is associated with the sea-ice environment yearround (e.g. the 4 pinniped species and Antarctic minke whales). We applied multiple biodiversity measures to explore trends in marine mammal community composition over various spatial and temporal scales and in relation to local sea-ice concentrations.

\section{MATERIALS AND METHODS}

Passive acoustic records were collected with a suite of autonomous passive acoustic recording device types attached to deep-sea moorings of the Hybrid Antarctic Float Observation System (HAFOS; Reeve et al. 2016); see Table 1 for a summary of recording and deployment specifications for sites 1-6 (Fig. 1). The sample rate of all recording devices allowed reliable identification of baleen whales and pinnipeds, but excluded (reliable) identification of all odontocete species except killer whales. In addition to clicks, killer whales also produce pulsed calls and whistles, which fell within our recording range and were used for species identification.

For all passive acoustic data, daily presence information for marine mammal species was extracted during manual analyses of the data using RAVEN Pro 1.5 (Bioacoustics Research Program 2019). Spectro- 


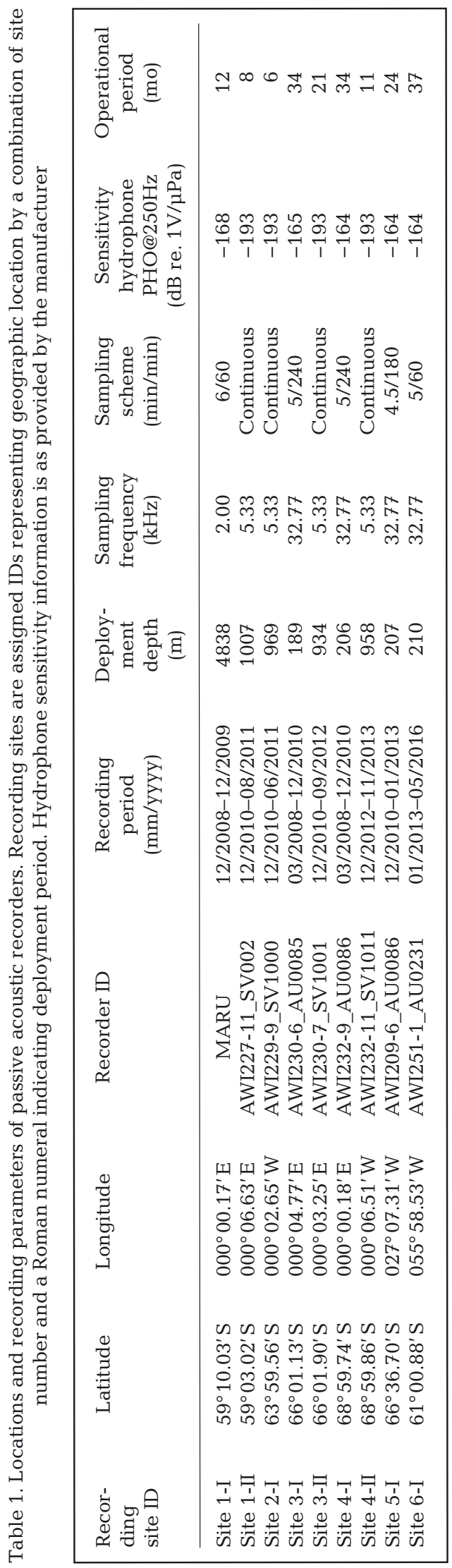

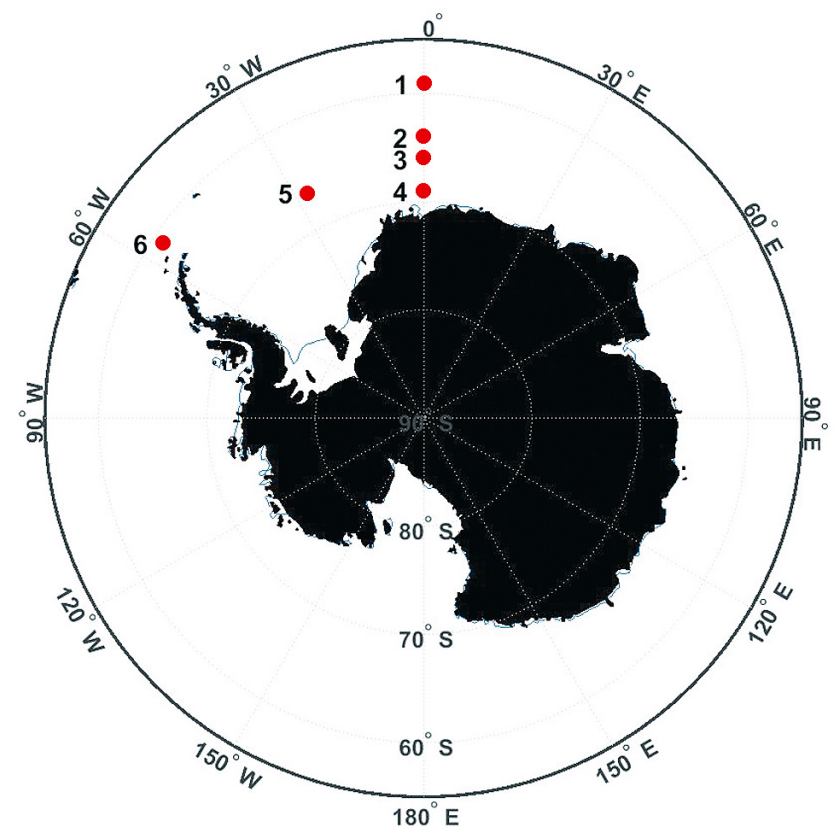

Fig. 1. Map showing the 6 locations (red dots) in the Southern Ocean, section Weddell Sea, bordered to the west by the Western Antarctic Peninsula (WAP), where passive acoustic records were collected

grams were visually and aurally scanned for vocalizations of marine mammals and anthropogenic noise (originating from seismic investigations and vessels). Spectogram settings (Hanning window, overlap: $50 \%$; fast Fourier transform: 512 points for sites 1-5, 16000 points for site 6 , in both cases resulting in a time resolution of $2 \mathrm{~s}$ and a frequency resolution of $0.5 \mathrm{~Hz}$ ) were kept constant throughout the analysis procedure. Overall, 9 marine mammal species were found present, although not all species were present at all sites. The marine mammal species that were acoustically identified in the recordings comprised 4 pinniped species (Weddell seal Leptonychotes weddellii, leopard seal Hydrurga leptonyx, crabeater seal Lobodon carcinophaga and Ross seal Ommatophoca rossii) and 5 cetacean species (Antarctic blue whale Balaenoptera musculus intermedia, fin whale Balaenoptera physalus, Antarctic minke whale Balaenoptera bonaerensis, killer whale Orcinus orca and humpback whale Megaptera novaeangliae).

Acoustic signatures were identified to species based on previous work (e.g. Širović et al. 2004, Rankin et al. 2005, Van Opzeeland 2010, Risch et al. 2014, Schall \& Van Opzeeland 2017).

Given that the data were collected with different recorders and recording parameters (Table 1), we used a subset of the data that was recorded at the same site during the same period, but with 2 different recorder types to assess the effect of recorder type 
and recording duty cycle on the daily acoustic presence assessments. On the level of daily acoustic presence, both recorders produced identical data for Antarctic blue, fin and Antarctic minke whales and Ross seals. For the other species, accordance between both data sets was $>77 \%$ (see Text A1 in the Appendix).

\subsection{Pseudo-abundance data}

Our data recorded daily presence and absence for each of the 9 target species, without information on abundance. However, we were able to calculate a relative abundance using the sum of days in a month on which a species was recorded. A larger population size is assumed to lead to more consistent recording, hence more days during which the species is recorded, whereas small populations are more likely to produce lower acoustic presences per month. We used this to calculate the monthly effective number of species (ENS), which has been shown to be the most robust diversity measure in relation to sampling effort and rank-abundance distributions (Chase \& Knight 2013). ENS refers to the true species diversity entailing the number of species in a community if all were equally common. In contrast to raw species richness, it is mainly influenced by dominant species and does not reflect the fluctuation of rare species around detection limits, which makes it less sensitive to detection probabilities.

To assess how species richness develops over time, we used the species exchange ratio (SER; see Hillebrand et al. 2018b for equations), which measures the proportional exchange of species between an earlier and a later sample in a time series. The richness-based species exchange ratio $\mathrm{SER}_{\mathrm{r}}$ is the Jaccard index, which is based on presence-absence only and quantifies changes in species identity. The abundancebased $\mathrm{SER}_{\mathrm{a}}$ is a measure of turnover that also takes into account changes in species proportional abundances . It is derived from Wishart's dissimilarity ratio (Hillebrand et al. 2018b), which, like ENS, is based on Simpson's index of dominance. Both $\mathrm{SER}_{\mathrm{r}}$ and $\mathrm{SER}_{\mathrm{a}}$ approach 0 if species identity and dominance structure do not change, and approach 1 if all species are replaced or shifted in their dominance. $\mathrm{SER}_{\mathrm{a}}$ reduces to $\mathrm{SER}_{\mathrm{r}}$ when all species are equally common.

\subsection{Ice concentration data}

The sea-ice concentration data used for this study were extracted from satellite images with a resolution of $6.25 \times 6.25 \mathrm{~km}$ from the Advanced Microwave Scanning Radiometer for EOS (AMSR-E) satellite sensor (Spreen et al. 2008). Monthly sea-ice concentration values were calculated in a radius of $30 \mathrm{~km}$ around each mooring. A $30 \mathrm{~km}$ radius was chosen based on a previous conservative detection range estimate for the Weddell Sea for a RAFOS sound source (emitting at $260 \mathrm{~Hz}$ ), an oceanographic instrument (see Spiesecke 2017 for details). Antarctic pinnipeds, humpback whales and Antarctic minke whales all produce sound in the same frequency range. For killer whales, producing sounds at higher frequencies, maximum detection ranges were reported to be $30 \mathrm{~km}$ based on studies from other areas (e.g. Burham et al. 2016). For the large baleen whales, detection ranges are known to be larger (i.e. $100 \mathrm{~km}$; Thomisch et al. 2016). However, comparison between data from both radii revealed ice concentration for 30 and $100 \mathrm{~km}$ to be highly similar for all 6 sites (Fig. A1). A $30 \mathrm{~km}$ radius was therefore selected to best fit the range over which all species included in the analyses were acoustically detected.

\subsection{Species co-occurrences}

The co-occurrence analysis was performed using the R package co-occur (Griffith et al. 2016), which is based on the probabilistic model by Veech (2013). This method does not require randomizations, but compares the observed number of co-occurrences of any species pair to the prediction based on the occupancy of each single species.

\section{RESULTS}

All sites showed clear seasonal variation in relative abundance (i.e. the proportion of days a species was acoustically present per month) of marine mammal species (Fig. 2). Furthermore, all sites where recording time was $>1$ yr showed clear seasonal variation in the ENS (Fig. 3a). Diversity peaked in austral late spring and early summer, shortly before seasonal sea-ice break-up for sites 3, 4 and 5. ENS was lowest during austral summer, when ice cover was low at these locations. At site 6, ice cover was substantially lower throughout the year, reaching maximum concentrations of $40 \%$ during austral winter. Diversity nevertheless followed the same cycle as at the sites with more extensive sea-ice cover. In austral winter, species relative abundance did not decrease below 1 , supporting all-year presence of at least some of the 


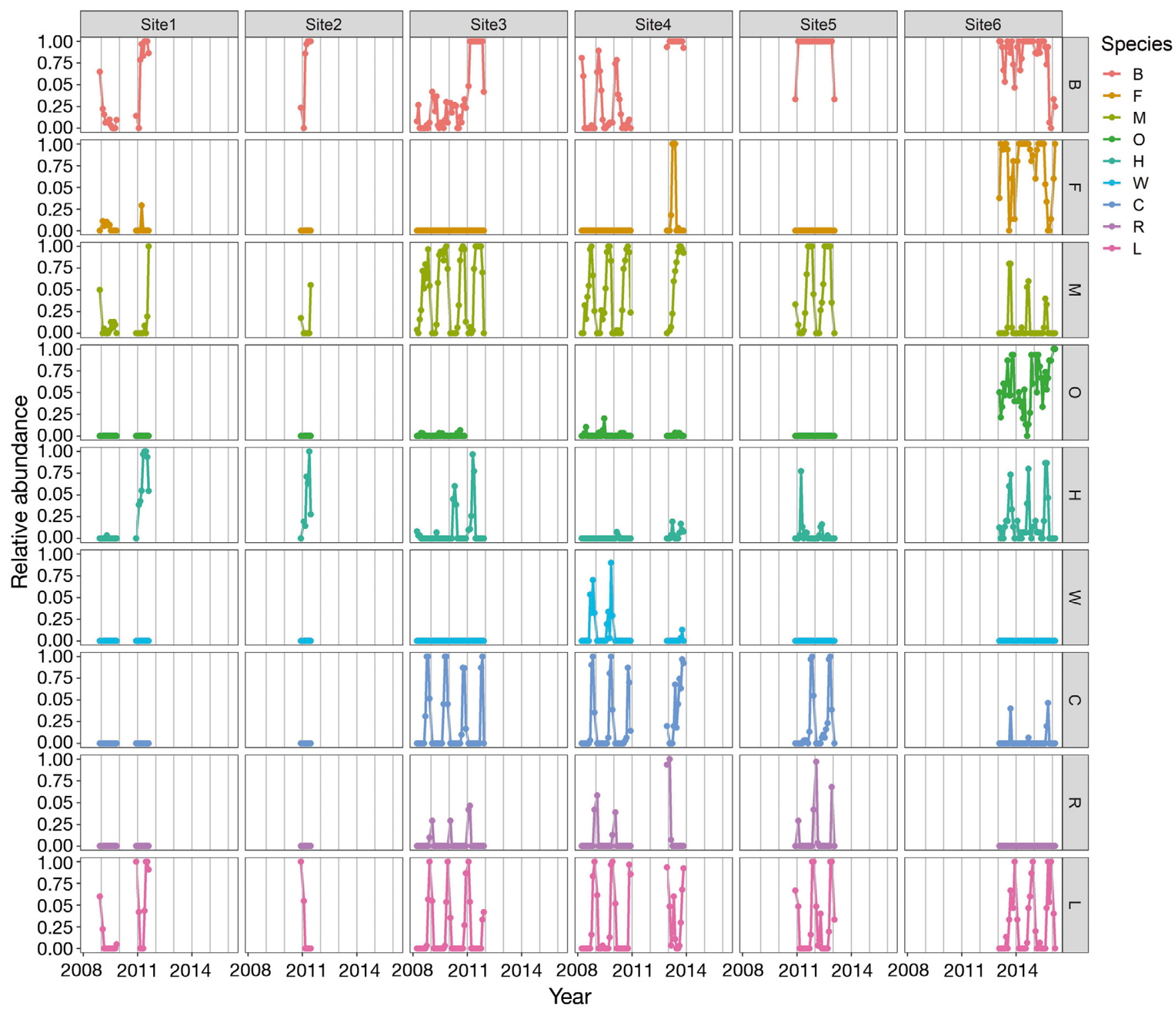

Fig. 2. Relative abundance of 9 marine mammal species for the 6 recording sites, given as the proportion of days in a month a species was recorded $(1=$ all days, $0=$ no days). Grey vertical lines indicate the start of each year, times without data points equal the times without recording at this site. B: Antarctic blue whale; F: fin whale, M: Antarctic minke whale; O: killer whale; H: humpback whale; W: Weddell seal; C: crabeater seal; R: Ross seal; L: leopard seal

study species (Fig. 2). At site 6, species richness was generally higher, fluctuating between 6 and 3 during austral summer and winter, respectively. At site 4, after resuming measurements in 2013 after a 2-yr pause, we found on average greater species diversity than before.

Consequently, the net change in species richness was rather neutral over time (Fig. 3b). The number of species gained or lost compared to previous sampling points followed a recurring seasonal cycle, with most increases in species richness occurring when sea-ice concentrations started to decline, and peak de- creases in species richness often occurring during low ice cover periods and prior to sea-ice formation.

Comparing each pair of time points within a site, we found clear seasonality in the temporal trends of ENS (Fig. 4a). This seasonal pattern was visible at all sites with time series $>1 \mathrm{yr}$, where the change in ENS was minimal over a time period of $1 \mathrm{yr}$ and maximal (both increases and decreases) over a time period of 0.5 yr. The longest data sets (sites 3 and 4) showed accumulating changes in ENS over time, indicating a temporal trend, whereas site 6 showed little variation over seasons and over years. 

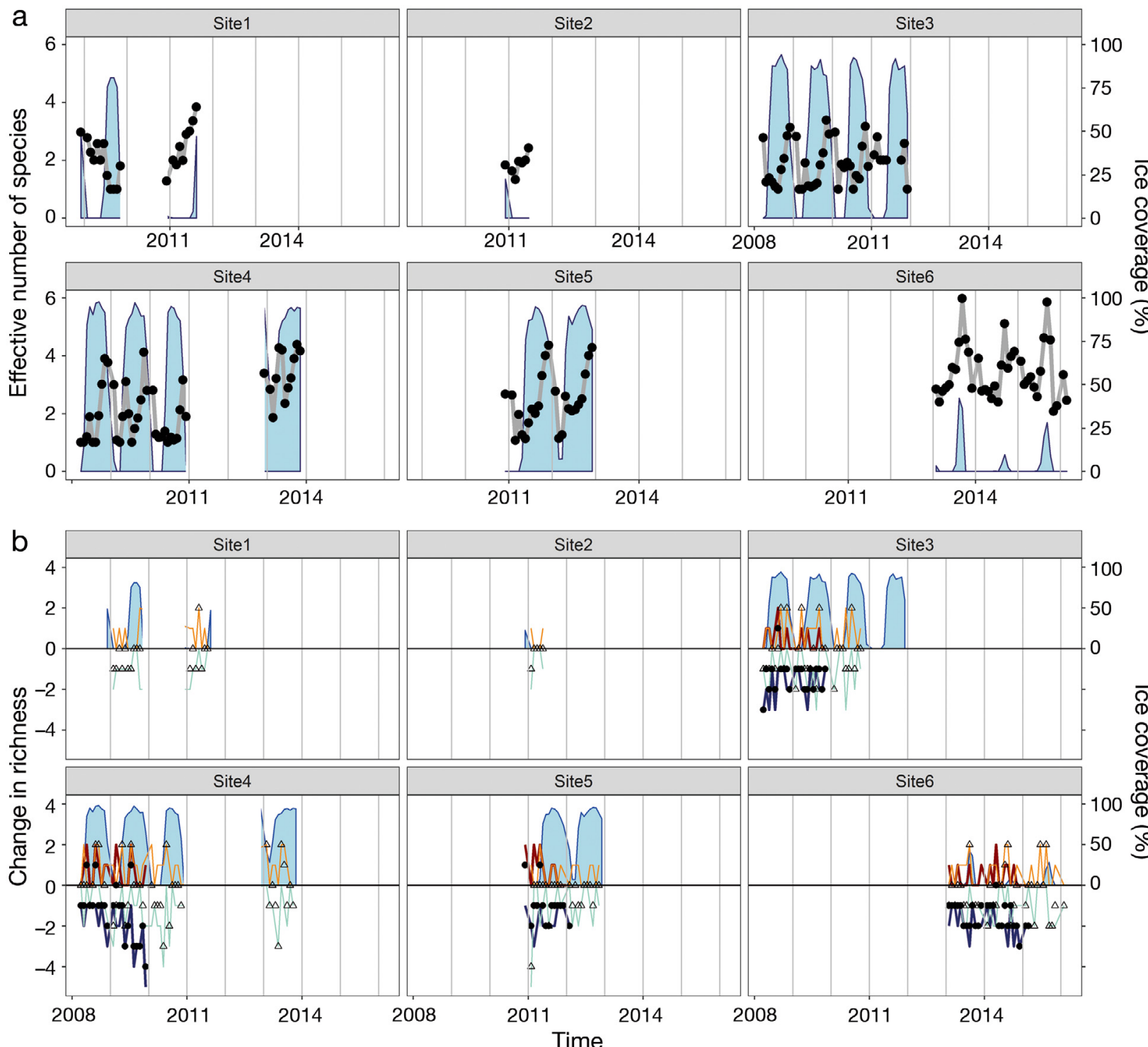

Fig. 3. Temporal trends in monthly species diversity for recording sites 1-6 in the Weddell Sea in relation to sea-ice concentration in a $30 \mathrm{~km}$ radius. Light blue shaded areas represent ice concentration in \% (right $y$-axis) and also denote the time frame of recording at each site. (a) Effective number of species (ENS) over time calculated from relative abundances of all species (as in Fig. 2) in a given month (black symbols). (b) Changes in species richness for each recording site over time. Data points show the net change in species richness from any month to the next month (open triangles) and to the same month next year (closed circles). Net richness change is the difference in species newly recorded in the next month (orange line) or the same month next year (red line) and species no longer recorded next month (aquamarine line) or same month next year (blue line)

Taking species identity into account, the richnessbased species exchange ratio $\left(\mathrm{SER}_{\mathrm{r} i}\right.$ Fig. $\left.4 \mathrm{~b}\right)$ revealed substantial seasonal variability in species composition at all 6 sites and-again for the longest time series - a trend of increasing compositional difference over longer time scales (site 4). The pattern became even more evident when relative dominance was included in the abundance-based $\mathrm{SER}_{a}$ (Fig. 4c). Thus, the change in composition over time was partly caused by changing dominance in addi-
Fig. 4. Changes in mammal species diversity with increasing temporal distance. Data points indicate comparison between each time point to each subsequent time point at a site; blue lines indicate a LOESS function $(\operatorname{span}=0.25$ ) for visualization. Vertical lines indicate exact yearly distances. (a) Change in monthly ENS with temporal distance. (b) Richness-based species exchange ratio $\left(\mathrm{SER}_{\mathrm{r}}\right)$ showing identity turnover with temporal distance. (c) Abundance-based species exchange ratio $\left(\mathrm{SER}_{\mathrm{a}}\right)$ with temporal distance accounting for the relative abundances of species, i.e. the proportion of days in a month a species was recorded 

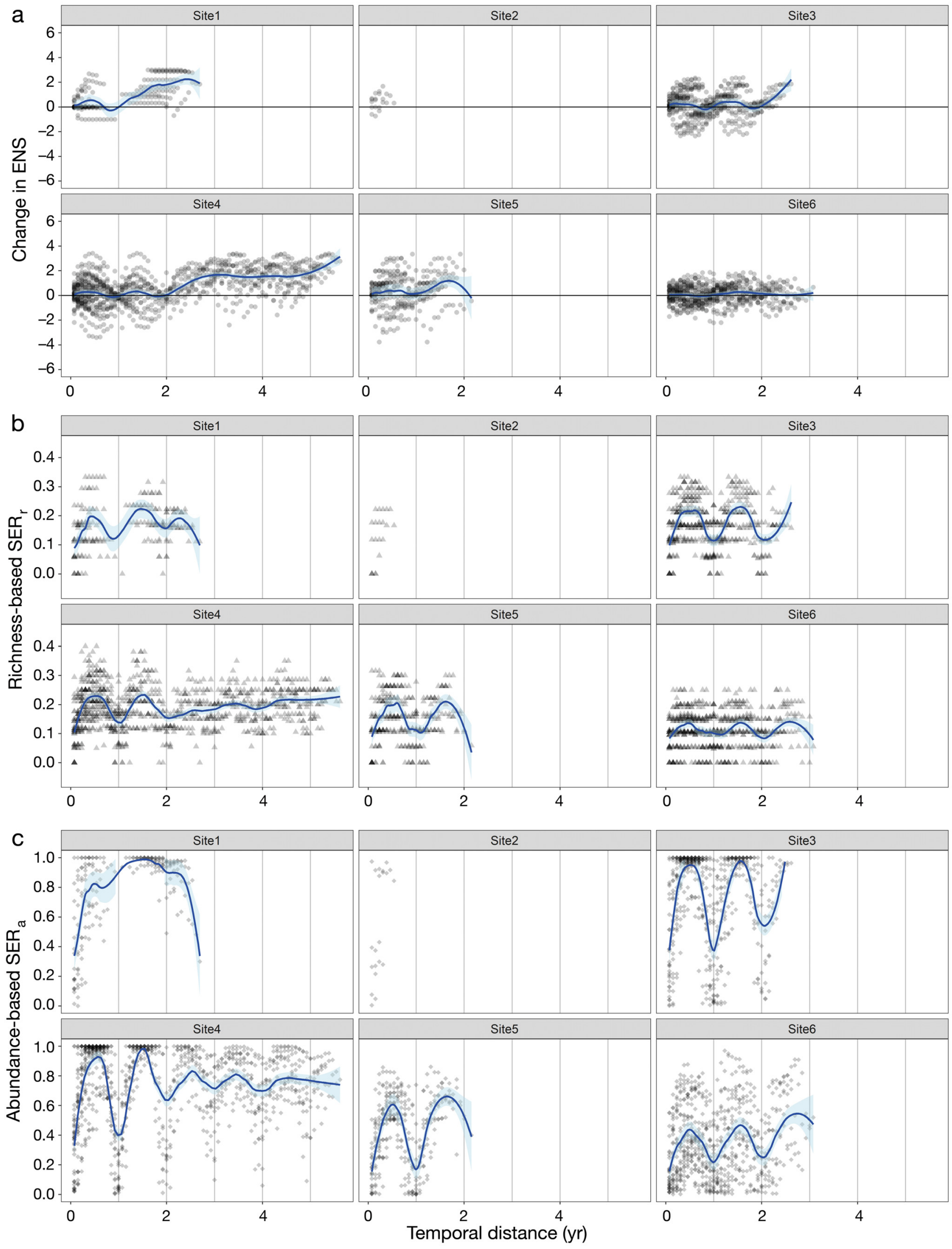
tion to changes in species identity, especially at sites $1,3,4$, and 6 . The sites with the longest time series (sites 3 and 4 ) exhibited a pattern that is remarkable in 3 aspects. First, species turnover between seasons is almost complete, i.e. over a time period of $0.5 \mathrm{yr}$ we observe complete changes in community composition (dissimilarity $=1$ ). Second, for some years (e.g. years 1 and 2), the community composition completely recovers annually, i.e. the same species with the same dominance structure appeared again (dissimilarity $=0$ ). Third, over longer time scales (3 or more years), this annual pattern becomes weaker, indicating a compositional drift over years, where dominance patterns change (Fig. 4c).

Comparing species co-occurrence at each site for all realized pairs (Fig. 5), some of these showed consistently negative relationships in their acoustic occurrence: Antarctic minke whales versus Ross seals, killer whales versus Antarctic blue whales, fin versus Antarctic minke whales as well as crabeater vesus Ross seals. Consistently positive relationships existed between leopard and Ross seals as well as between leopard and crabeater seals. Some species relationships were reversed when comparing the 5 oceanic sites versus site 6: Antarctic minke whales and Antarctic blue whales, Antarctic minke whales and humpback whales as well as humpback whales and leopard seals all showed a positive association at the Western Antarctic Peninsula (WAP), whereas their association was negative or random at the oceanic recording sites.

\section{DISCUSSION}

The still relatively new research field of ecoacoustics (Sueur \& Farina 2015), has developed a large variety of metrics and tools to assess biodiversity from terrestrial acoustic remote sensing data (e.g. Pijanowski et al. 2011, Sueur et al. 2014). Nevertheless, successful applications of passive acoustic methods to characterize communities and species richness in aquatic environments have, in some cases, proved not to be straightforward (e.g. Parks et al. 2014, Desjonquères et al. 2015, Buxton et al. 2018). Application of these metrics to aquatic passive acoustic data requires re-evaluation of existing metrics and potentially developing new approaches before they can be reliably used for underwater biodiversity assessments (see Risch \& Parks 2017 for a review, Roca \& Van Opzeeland 2019). Here, we applied biodiversity metrics normally used for count data to hand-
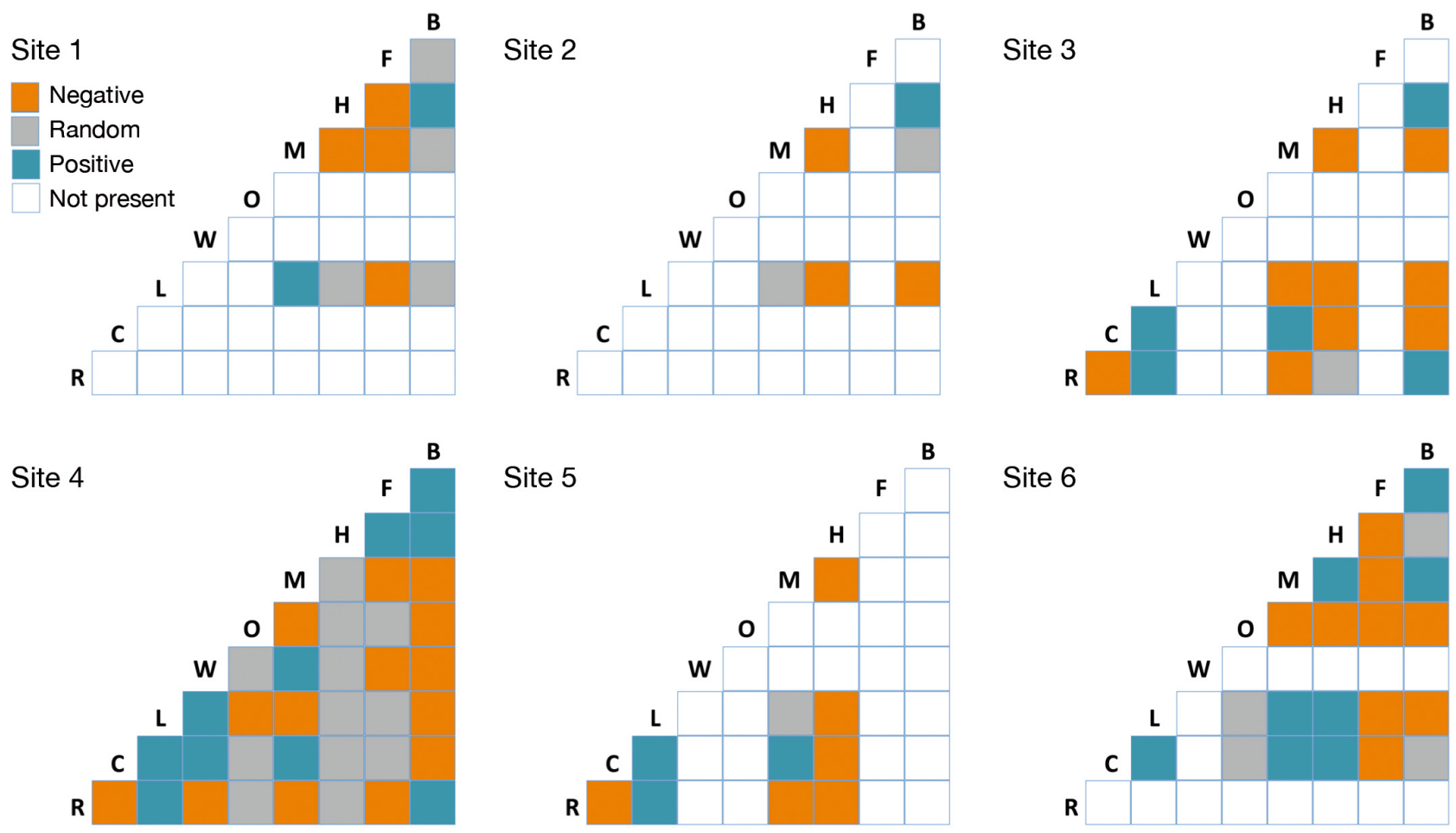

Fig. 5. Species co-occurrence showing significant negative (orange), positive (blue) and random (grey) associations between species for each of the 6 sites. White squares indicate that one or both species were not present at this site (hence no interaction). For species abbreviations, see legend of Fig. 2 
browsed audio data to explore spatio-temporal patterns in species composition of marine mammals. Although hand-browsing passive acoustic data can be relatively time-consuming, the daily presence data used in this study were performed in the context of standard data quality checks as part of ongoing work. Hand-browsed data have the advantage that they provide highly reliable information on the presence of vocalizing marine mammals and information can be collected for all species simultaneously. Daily species presence information suffices to explore large-scale patterns in community composition while still ensuring feasible processing times when using multi-site and multi-year data. Furthermore, for future applications, this combination of methods also allows inclusion of archived passive acoustic recordings from which daily presence information can be extracted in retrospect to explore how communities have developed when, for example, composition is compared over even longer time frames.

In this study, we included data from recorders that collected data continuously as well as from recorders that were programmed to record on a duty cycle. Depending on vocal behavior of the study species, duty cycling recordings can affect the likelihood of detection (Thomisch et al. 2015). Evaluations of a subset of the data collected by 2 different, but simultaneously recording devices (see Text A1) showed that duty cycling affected daily presence for some species, but that accordance on daily acoustic presence was still $>77 \%$ between both devices for all species. Nevertheless, care should be taken when using duty cycled recordings for community studies, as, for example, strong diel patterns in vocal activity of a species may strongly affect the detectability and thereby bias acoustic and species diversity results (Thomisch et al. 2015).

A further methodological aspect that may affect the likelihood of detecting calling animals concerns the underwater ambient noise conditions. Menze et al. (2017) showed for the Weddell Sea that with increasing sea-ice concentration, area and thickness, sound levels decreased while the contribution of distant sources increased. For future applications, the vocalizations that exceed a certain amplitude threshold could be included in analyses, thereby automatically 'filtering' to include only the calls from animals within a certain radius of the recorder that are less susceptible to masking by fluctuations in environmental sound levels. This approach would have the additional advantage that data are more likely to represent 'actual acoustic communities', i.e. species that are likely to acoustically interact as they occur within each other's acoustic space (Van Opzeeland \& Boebel 2018).

\subsection{Application of biodiversity measures}

Although multi-year passive acoustic data sets from the Southern Ocean are becoming increasingly available (see Van Opzeeland et al. 2013b for an overview), information on spatio-temporal patterns in multi-species acoustic assemblages from this region are still relatively rare (Širović et al. 2009, Van Opzeeland et al. 2010). Alongside presenting a firsttime application of biodiversity metrics to marine mammal passive acoustic monitoring data, the outcomes of the present study represent a unique bird's eye perspective on the spatio-temporal dynamics of multi-species acoustic assemblages. At the same time, the analyses of biodiversity change often depend on active assessments (field observations), whereas passive methods add the dimension of collecting continuous records, which makes the assessment of species presences much more reliable. Thereby, the overestimation or underestimation of biodiversity change becomes much less likely.

The assessment of temporal and spatial turnover in biodiversity has gained much interest in recent years, as major synthesis efforts showed that the global erosion of biodiversity does not necessarily lead to local species loss, but to accelerated turnover (Dornelas et al. 2014, Blowes et al. 2019). Passive acoustic monitoring data thus open an opportunity for longterm observation, especially as hydrophone networks allow the collection of both spatially and temporally highly resolved data. Most time series are analysed in isolation, but a recent analysis of plant data highlighted that the strongest constraint on temporal change in composition can be the lack of spatial heterogeneity (Hodapp et al. 2018).

\subsection{Acoustic presence-absence data}

When using passive acoustic data to derive species presence information, it is important to keep in mind that the information is restricted to acoustic presences. In the situation where an animal is physically present, but not producing sound, it will be logged as acoustically absent. The representativeness of acoustic presence for physical presence therefore is strongly dependent on the likelihood of an animal producing sound, and physical and acoustic presence should not, by definition, be assumed equal. Some species are known to produce sound virtually year-round (e.g. Weddell seals: Van Opzeeland et al. 2010; Antarctic blue whales: Thomisch et al. 2016), whereas for other species, acoustic activity is re- 
stricted to the breeding season (see Van Parijs 2003 for a review). For these species, patterns in species richness, to a large part, reflect the seasonal fluctuations in reproductive activity, not excluding that the species remains present (but is silent) in the area beyond the breeding season (e.g. Ross seals). For other species, acoustic presence or absence reflects migratory movements, i.e. the absence of sounds reflects 'true' absences, albeit periodic (e.g. fin whales, killer whales). Furthermore, the likelihood of a species to produce sound may also depend on local factors such as foraging conditions, habitat type and behavioral state, and may therefore also differ between sites.

In spite of the above-mentioned caution that needs to be taken when interpreting the acoustic presence-absence data, the current approach allows a new perspective on the dynamics of acoustic communities over time and between localities. This in turn, allows addressing ecological and conservation questions on the community level which hitherto has been little studied in marine mammals. In the light of ongoing environmental changes occurring virtually worldwide, an improved understanding of the shifts and irregularities in the timing of behaviors and community composition can boost interpretation of responses to changing environmental processes.

\subsection{Species richness and diversity}

\subsubsection{Overall patterns}

A total number of 9 marine mammal species were identified in the passive acoustic data sets included in this study. This comprises $45 \%$ of the total species richness known to occur in Antarctic waters (i.e. Southern Ocean, $>60^{\circ} \mathrm{S}$ ), where 6 pinniped, 7 mysticete and 7 odontocete species are known to occur (e.g. Boyd 2002, Gill \& Evans 2002). It is important to acknowledge that the limited bandwidth of the recordings (i.e. 5 and $16 \mathrm{kHz}$ for the SonoVault and the AURAL, respectively) only allowed inclusion of only one of the odontocete species (killer whale), as reliable species identification in the higher frequency bands - where many of the odontocetes produce sounds - was not possible. Furthermore, of the 6 pinniped species, only the 4 species identified here exhibit an aquatic mating system and produce underwater sounds (see Van Parijs 2003 for a review). The other 2 species, southern elephant seals Mirounga leonina and Antarctic fur seals Arctocephalus gazel$l a$, breed on land and produce sound in air only
(Rogers 2003). The absence of 3 of the Antarctic mysticete species in the recordings is likely explained by their distribution, which does not extend as far south as the other species, making acoustic detections of these species less likely at the positions where data were collected during this study (e.g. Boyd 2002, Gill \& Evans 2002).

\subsubsection{Spatial patterns}

Species diversity was largest at sites 4 and 6 (9 and 7 species present, respectively). Of the 6 sites, sites 4 and 6 are closest to shore. Recordings from PALAOA, a shelf-ice-based passive acoustic observatory $\left(70^{\circ} 31^{\prime} \mathrm{S}, 8^{\circ} 13^{\prime} \mathrm{W}\right.$; Boebel et al. 2006), also revealed a similarly high species richness (10 species; Van Opzeeland 2010). These relatively high local species diversities at sites in proximity to shore may be explained by the regular occurrence of open water or polynyas (i.e. areas with open water within ice cover; Wendler et al. 1997) caused by catabatic and westerly winds pushing the ice in northern directions. Polynyas provide food resources year-round and persistent open water, where marine mammals can surface to breathe (Malpress et al. 2017). For site 6, off the WAP, ice cover is less persistent and the presence of polynyas may therefore not be as significant for marine mammals as at other sites. The area off the WAP is known to be biologically rich due to unique physical forcing mechanisms (i.e. local upwelling of the Upper Circumpolar Deep Water; Prézelin et al. 2004) enhancing primary production and thereby supporting a persistent and large standing stock of Antarctic krill Euphausia superba (Siegel et al. 1998, Lascara et al. 1999). Large populations of marine top predators are known to depend entirely or to a large extent on Antarctic krill as a food source (Costa \& Crocker 1996, Fraser \& Trivelpiece 1996). The relatively persistent and reliable local availability of food sources in this area and other areas off the WAP has also been related to the occurrence of cetacean super-aggregations (Nowacek et al. 2011, Burkhardt \& Lanfredi 2012) and may furthermore explain the comparably large species diversity, also outside the austral summer season, observed here. It cannot be excluded that these different ecological conditions off the WAP also result in differences in vocal behavior of species, e.g. resulting in greater acoustic presence of species than at other sites. However, comparisons of community data over time within this site will not suffer from this potential bias, and it may be of particular interest to monitor trends over time in light 
of the rapid climate-induced changes in the WAP area (e.g. Gutt et al. 2015).

\subsubsection{Seasonal patterns}

Community composition dynamics followed a highly similar seasonal cycle, coupled with the sea-ice concentration, virtually independent of the spatial distance between recording sites. Despite local differences in (acoustic) abundance of species, community composition was highly similar between even the most distant site pairs. This observation tentatively suggests that at the level of top predators, the Weddell Sea may be regarded as one ecoregion, comprising similar environmental conditions (e.g. Bailey 2004) and an assemblage of species that is similar within the ecoregion but different from surrounding ecoregions.

Species richness exhibited a strong seasonal pattern and generally peaked at all sites in late austral spring and early summer, shortly before sea-ice break-up. This period coincides with the mating period of the 4 ice-breeding pinniped species, during which speciesspecific peaks in calling activity are known to occur (Van Opzeeland et al. 2010), and hence these species acoustically dominate the recordings in this period. Furthermore, for humpback, fin and Antarctic blue whales, their spring/summer acoustic presence at the recording sites reflects animals migrating southbound from their respective breeding areas towards the Antarctic continent in the course of austral summer, following the highly productive marginal ice-edge zone associated with the receding sea-ice edge (FebMar; Bombosch et al. 2014, Thomisch et al. 2016). The tight connection between the timing of sea-ice breakup and peak species diversity most likely reflects the increased light availability in the water column, which results in a bloom of pelagic phytoplankton, attracting large grazing populations that are in turn targeted by baleen whales and Ross, leopard and crabeater seals. The purpose of the sounds produced by marine mammal species on their Antarctic feeding grounds and during migration is poorly known. Given that part of the vocalizations is known to play a role in breeding contexts, calling has been suggested to be related to en-route opportunistic mating between (non-dominant) males and females that failed to conceive on the breeding grounds (e.g. Clapham 1996, Thomisch et al. 2016). Other sounds may be produced in social contexts or function to coordinate foraging behavior among conspecifics (Rekdahl et al. 2015, Lewis et al. 2018).
Species richness dropped substantially at all sites during austral winter, but never dropped below 1 . When species identity and dominance were taken into account, complete species turnover was observed followed by full annual compositional recovery. This full community replacement is remarkable and stronger than that observed for other organism groups at temperate or even lower latitudes (see e.g. Hillebrand et al. 2018b). We propose that this turnover reflects the very strong seasonal fluctuation in environmental conditions in polar regions. Antarctic minke whales, for example, exhibited an almost opposite seasonal pattern in acoustic presence compared to the other species, producing sounds almost exclusively during austral winter (Dominello \& Širović 2016). This ice-adapted species has a strong rostrum with which it is known to create its own breathing holes in ice-covered areas (Leatherwood et al. 1981). This adaptation likely enables the species to exploit under-ice krill resources during winter that are not available to other species (Williams et al. 2015). At some sites, dissimilarities in richness and composition between seasons were not that extreme, e.g. caused by the presence of polynyas, creating persistent areas with open water throughout winter. This also supports the findings of previous studies that certain species are pervasively present in Antarctic waters (e.g. humpback whales: Van Opzeeland et al. 2013a; Antarctic blue whales: Thomisch et al. 2016).

At site 6, the number of species did not drop below 3 for the majority of the time, and Antarctic blue, fin and killer whales remained acoustically present throughout the year. The latter 2 species exhibited atypical seasonal patterns when site 6 was compared to the other recording locations. For fin whales, the area off the WAP close to the recording location, as mentioned earlier, is known for its annually reoccurring large fin whale feeding aggregations, most likely due the exceptional productivity of this area (Prézelin et al. 2004, Burkhardt \& Lanfredi 2012).

For killer whales, the aberrant pattern in occurrence at site 6 (Fig. 2) possibly reflects ecological differences at this site, such as the fact that sea-ice cover is lower here compared to the oceanic sites. In killer whales, different ecotypes are known to occur in the Southern Ocean (types A, B, C and D: Pitman \& Ensor 2003, Pitman et al. 2011), each with typespecific morphology, feeding strategies and distribution. Type Bs are thought to occur mainly off the WAP, whereas type Cs have mainly been observed in pack-ice areas and off the Antarctic continent (Pitman \& Ensor 2003). In northern hemisphere killer 
whale populations, differences in dietary specalizations between different killer whale ecotypes are known to have led to behavioral specializations, leading to substantial differences in acoustic behavior as well (Deecke et al. 2011, Riesch et al. 2012). Although for Southern Ocean populations, data on ecotype-specific acoustic behavior to date are too limited for such conclusions (see Schall \& Van Opzeeland 2017), it cannot be excluded that the observed patterns may be explained by diverging ecotype-specific behavior between the recording sites.

\subsection{Species co-occurrence}

The co-occurrence analysis revealed a number of consistently positive and consistently negative associations in the occurrence of species across sites. Interestingly, for some species pairs, the relationship was reversed at the WAP when compared to the other sites.

Part of the association patterns can likely be attributed to persistent coincidences or discordances in the timing of acoustic behavior. The consistently positive association between Ross and leopard seals is likely attributed to the overlap in timing of acoustic behavior (Van Opzeeland et al. 2010), which persistently follows the same pattern across all study sites where both species are present. Similarly, the consistently negative association in the occurrence of Antarctic minke whales and Ross seals as well as between crabeater and Ross seals is a consequence of the strong seasonality in the respective acoustic activity of these species, precluding the occurrence of temporal acoustic overlap.

The positive association between leopard and crabeater seals across sites potentially reflects the predator-prey relationship between the 2 species. Leopard seals are generalist apex predators capable of adjusting their foraging behavior to available food sources (Siniff \& Stone 1985, Lowry et al. 1988, Casaux et al. 2009). Preferred prey differs between seasons and regions, but is known to seasonally also include weaned crabeater seal pups (Gilbert \& Erickson 1977). The consistently positive association in leopard and crabeater seal acoustic occurrence across sites suggests that leopard seals may anticipate their presence to coincide with the period during which most crabeater seal pups are weaned. A further association between the 2 species may be based on the fact that both forage on the same size of Antarctic krill and may therefore in some areas, e.g. the WAP, target the same regions (Siniff \& Bengtson 1977, Lowry et al. 1988).

In this study, fin and Antarctic minke whales were consistently negatively associated in occurrence. Santora et al. (2010) found both species foraging on Antarctic krill alongside humpback whales off the WAP in January and showed that all 3 baleen whale species co-occurred, targeting different krill sizes, indicative of resource partitioning between species. The negative co-occurrence pattern observed here based on the passive acoustic data is likely the consequence of the strong seasonality in Antarctic minke whale sound production, occurring exclusively between April and December (Van Opzeeland 2010). Instead, the negative association between fin and Antarctic minke whales found in this study possibly reflects contrasting habitat preferences during the time both species are vocally active; opposite to Antarctic minke whales, fin whales are known to avoid ice-covered areas (Širović et al. 2004, Williams et al. 2015).

Another species pair that was consistently negatively associated was Antarctic blue whales and killer whales. Predatory interactions with killer whales have been documented for blue whales (see Ford \& Reeves 2008). Mammal-eating killer whales are the only known natural predator of baleen whales. Although not all killer whale ecotypes occurring in Antarctic waters eat mammals, blue whales may nevertheless associate killer whale calls in general with predation threat and avoid areas where killer whales are present or remain silent in their presence (Tyack et al. 2011).

Lastly, 3 species pairs exhibited a positive association in occurrence only at the recording site off the WAP. The fact that more species are found to cooccur off the WAP compared to other sites may also reflect that the higher abundance of prey off the WAP attracts, alongside regular open-water species such as humpback whales, ice-adapted species such as leopard seals and Antarctic minke whales. Through behavioral plasticity, some of these iceassociated species may adapt behavior to effectively exploit food resources in the absence of ice. For example, the leopard seal summer population off the WAP is known to seasonally haul out on land (instead of on ice, as observed for all other leopard seal populations) and also differs in aspects of their diving behavior, thought to reflect their krill foraging specialization off the WAP (Hall-Aspland \& Rogers 2004, Krause et al. 2015). Similarly, Antarctic minke and humpback whales exhibited a positive association in occurrence only at the recording site off the WAP, but 
did not exhibit an association in their distribution based on acoustic data from the other sites or circumantarctic sightings data (Kasamatsu et al. 2000). However, several smaller-scale visual surveys also found both species to occur sympatrically off the WAP, both foraging on Antarctic krill (Thiele et al. 2004, Friedlaender et al. 2006). Possibly to overcome interference competition, both species were found to exploit krill layers at different depth regimes, thereby vertically partioning food resources (Friedlaender et al. 2009). The fact that the marine mammal assemblage off the WAP is comparatively somewhat larger and differently composed compared to the other sites is therefore most likely explained by the higher local krill abundances at this site.

\subsection{Outlook}

The present study has shown how a combination of methods allows monitoring marine mammal communities, including information on co-occurrences and potential implications for their interactions. By extending this to more recent and, where available, archived recordings, long-term trends in marine mammal seasonal behavior, space use and composition of multi-species assemblages can be explored. For many basins, long-term passive acoustic data are meanwhile available, allowing analyses over time scales of a decade or more. Furthermore, including information from other sound-producing species, such as fish and invertebrates, as well as environmental sound (e.g. anthropogenic noise), can provide further (year-round) contextual information on the ecological and acoustic quality of underwater marine habitats. In light of ongoing environmental changes, the potential of passive acoustic surveys and acoustic indices in the context of biodiversity and habitat quality monitoring is still heavily underexploited (Sueur et al. 2019). Particularly for the marine realm, these methods represent a source of untapped and hidden potential to become vital players for efficient large-scale environmental monitoring of the Earth's natural soundscapes.

Acknowledgements. We thank Olaf Boebel for coordinating the HAFOS observatory and its maintenance. We also thank the crews of RV Polarstern expeditions ANT-XXV/2, ANTXXIV/3, ANT-XXVII/2 and ANT-XXIX/2, and the mooring team of the AWI's physical oceanography department for the deployment and recovery of the acoustic recorders. We thank Stefanie Spiesecke for managing and cleaning the data, and Karolin Thomisch, Diego Filun, Rike Vooth, Ramona Matmueller and Malene Meister for manual annotation of the passive acoustic data sets included in this study.

\section{LITERATURE CITED}

Aguirre AA, Tabor GM (2004) Introduction: marine vertebrates as sentinels of marine ecosystem health. EcoHealth 1:236-238

Andreassen T, Surlykke A, Hallam J (2014) Semi-automatic long-term acoustic surveying: A case study with bats. Ecol Inform 21:13-24

Bailey RG (2004) Identifying ecoregion boundaries. Environ Manage 34:S14-S26

Blowes SA, Supp SR, Antão LH, Bates A and others (2019) The geography of biodiversity change in marine and terrestrial assemblages. Science 366:339-345

Boebel O, Kindermann L, Klinck H, Bornemann H and others (2006) Real-time underwater sounds from the Southern Ocean. Eos 87:361

* Bombosch A, Zitterbart DP, Van Opzeeland I, Frickenhaus S, Burkhardt E, Wisz MS, Boebel O (2014) Predictive habitat modelling of humpback (Megaptera novaeangliae) and Antarctic minke (Balaenoptera bonaerensis) whales in the Southern Ocean as a planning tool for seismic surveys. Deep Sea Res I 91:101-114

Boyd IL (2002) Antarctic marine mammals. In: Perrin WF, Würsig B, Thewissen JGM (eds) Encyclopedia of marine mammals. Academic Press, San Diego, CA, p 30-36

Burham RE, Palm RS, Duffus DA, Mouy X, Riera A (2016) The combined use of visual and acoustic data collection techniques for winter killer whale (Orcinus orca) observations. Glob Ecol Conserv 8:24-30

Burkhardt E, Lanfredi C (2012) Fall feeding aggregations of fin whales off Elephant Island (Antarctica). Paper SC/ 64/SH9 presented to the IWC Scientific Committee

Buxton RT, McKenna MF, Clapp M, Meyer E and others (2018) Efficacy of extracting indices from large-scale acoustic recordings to monitor biodiversity. Conserv Biol 32:1174-1184

* Casaux R, Baroni A, Ramón A, Carlini A, Bertolin M, DiPrinzio CJ (2009) Diet of the leopard seal Hydrurga leptonyx at the Danco Coast, Antarctic Peninsula. Polar Biol 32:307-310

Chase JM, Knight TM (2013) Scale-dependent effect sizes of ecological drivers on biodiversity: why standardised sampling is not enough. Ecol Lett 16:17-26

Clapham PJ (1996) The social and reproductive biology of humpback whales: an ecological perspective. Mammal Rev 26:27-49

Costa DP, Crocker DE (1996) Marine mammals of the Southern Ocean. Found Ecol Res West Antarctic Peninsula 70: 287-301

* Darras K, Batáry P, Furnas B, Celis-Murillo A, Van Wilgenburg SL, Mulyani YA, Tscharntke T (2018) Comparing the sampling performance of sound recorders versus point counts in bird surveys: a meta-analysis. J Appl Ecol 55:2575-2586

*ैDeecke VB, Nykänen M, Foote AD, Janik VM (2011) Vocal behaviour and feeding ecology of killer whales Orcinus orca around Shetland, UK. Aquat Biol 13:79-88

* Desjonquères C, Rybak F, Depraetere M, Gasc A, Le Viol I, Pavoine S, Sueur J (2015) First description of underwater acoustic diversity in three temperate ponds. PeerJ 3:e1393

* Dominello T, Širović A (2016) Seasonality of Antarctic minke whale (Balaenoptera bonaerensis) calls off the Western Antarctic Peninsula. Mar Mamm Sci 32:826-838

* Dornelas M, Gotelli NJ, McGill B, Shimadzu H, Moyes F, Sievers C, Magurran AE (2014) Assemblage time series 
reveal biodiversity change but not systematic loss. Science 344:296-299

Ford JKB, Reeves RR (2008) Fight or flight: antipredator strategies of baleen whales. Mammal Rev 38:50-86

Fraser WR, Trivelpiece WZ (1996) Factors controlling the distribution of seabirds: winter-summer heterogeneity in the distribution of Adélie penguin populations. Found Ecol Res West Antarctic Peninsula 70:257-272

Friedlaender AS, Halpin PN, Qian SS, Lawson GL, Wiebe $\mathrm{PH}$, Thiele D, Read AJ (2006) Whale distribution in relation to prey abundance and oceanographic processes in shelf waters of the Western Antarctic Peninsula. Mar Ecol Prog Ser 317:297-310

Friedlaender AS, Lawson GL, Halpin PN (2009) Evidence of resource partitioning between humpback and minke whales around the Western Antarctic Peninsula. Mar Mamm Sci 25:402-415

Gilbert JR, Erickson AW (1977) Distribution and abundance of seals in the pack ice of the Pacific Sector of the Southern Ocean. Adaptations within Antarctic ecosystems. Smithsonian Institution, Washington, DC, p 703-740

Gill A, Evans PGH (2002) Marine mammals of the Antarctic in relation to hydro-acoustic activities. Study on behalf of the German Federal Agency for Nature Conservation (BfN), Oxford

* Griffith DM, Veech JA, Marsh CJ (2016) cooccur: Probabilistic Species Co-Occurrence Analysis in R. J Stat Soft 69: $1-17$

Gutt J, Bertler N, Bracegirdle TJ, Buschmann A and others (2015) The Southern Ocean ecosystem under multiple climate change stresses - an integrated circumpolar assessment. Glob Change Biol 21:1434-1453

Hall-Aspland SA, Rogers TL (2004) Summer diet of leopard seals (Hydrurga leptonyx) in Prydz Bay, Eastern Antarctica. Polar Biol 27:729-734

Halpern BS, Frazier M, Potapenko J, Casey KS and others (2015) Spatial and temporal changes in cumulative human impacts on the world's ocean. Nat Commun 6:7615

* Hillebrand H, Brey T, Gutt J, Hagen W, Metfies K, Meyer B, Lewandowska A (2018a) Climate change: warming impacts on marine biodiversity. Handbook on Marine Environment Protection. Springer, Cham

* Hillebrand H, Blasius B, Borer ET, Chase JM and others (2018b) Biodiversity change is uncoupled from species richness trends: consequences for conservation and monitoring. J Appl Ecol 55:169-184

* Hodapp D, Borer ET, Harpole WS, Lind ME and others (2018) Spatial heterogeneity in species composition constrains plant community responses to herbivory and fertilisation. Ecol Lett 21:1364-1371

Kasamatsu F, Matsuoka K, Hakamada T (2000) Interspecific relationship in density among the whale community in the Antarctic. Polar Biol 23:466-473

Krause DJ, Goebel ME, Marshall GJ, Abernathy K (2015) Novel foraging strategies observed in a growing leopard seal (Hydrurga leptonyx) population at Livingston Island, Antarctic Peninsula. Anim Biotelem 3:24

Lascara CM, Hofmann EE, Ross RM, Quetin LB (1999) Seasonal variability in the distribution of Antarctic krill, Euphausia superba, west of the Antarctic Peninsula. Deep Sea Res I 46:951-984

Leatherwood S, Thomas JA, Awbrey FT (1981) Minke whales off northwestern Ross Island. Antarct J US 16:154

* Lewis LA, Calambokidis J, Stimpert AK, Fahlbusch J and others (2018) Context-dependent variability in blue whale acoustic behaviour. R Soc Open Sci 5:180241

Lotze HK, Lenihan HS, Bourque BJ, Bradbury RH and others (2006) Depletion, degradation, and recovery potential of estuaries and coastal seas. Science 312:1806-1809

K Lowry LF, Testa JW, Calvert W (1988) Notes on winter feeding of crabeater and leopard seals near the Antarctic Peninsula. Polar Biol 8:475-478

Malpress V, Bestley S, Corney S, Welsford D, Labrousse S, Sumner M, Hindell M (2017) Bio-physical characterisation of polynyas as a key foraging habitat for juvenile male southern elephant seals (Mirounga leonina) in Prydz Bay, East Antarctica. PLOS ONE 12:e0184536

Menze S, Zitterbart DP, Van Opzeeland I, Boebel O (2017) The influence of sea ice, wind speed and marine mammals on Southern Ocean ambient sound. R Soc Open Sci 4:160370

Milnes MR, Guillette LJ Jr (2008) Alligator tales: new lessons about environmental contaminants from a sentinel species. Bioscience 58:1027-1036

*Moore SE (2008) Marine mammals as ecosystem sentinels. J Mammal 89:534-540

Moore SE, Huntington HP (2008) Arctic marine mammals and climate change: impacts and resilience. Ecol Appl 18:S157-S165

Nowacek DP, Friedlaender AS, Halpin PN, Hazen EL and others (2011) Super-aggregations of krill and humpback whales in Wilhelmina Bay, Antarctic Peninsula. PLOS ONE 6:e19173

* Parks SE, Miksis-Olds JL, Denes SL (2014) Assessing marine ecosystem acoustic diversity across ocean basins. Ecol Inform 21:81-88

*Pijanowski BC, Farina A, Gage SH, Dumyahn SL, Krause BL (2011) What is soundscape ecology? An introduction and overview of an emerging new science. Landsc Ecol 26: 1213-1232

Pitman RL, Ensor P (2003) Three forms of killer whales (Orcinus orca) in Antarctic waters. J Cetacean Res Manag 5: 131-140

*Pitman RL, Durban JW, Greenfelder M, Guinet C and others (2011) Observations of a distinctive morphotype of killer whale (Orcinus orca), type D, from subantarctic waters. Polar Biol 34:303-306

* Prézelin BB, Hofmann EE, Moline M, Klinck JM (2004) Physical forcing of phytoplankton community structure and primary production in continental shelf waters of the Western Antarctic Peninsula. J Mar Res 62:419-460

Rankin S, Ljungblad D, Clark C, Kato H (2005) Vocalizations of Antarctic blue whales, Balaenoptera musculus intermedia, recorded during the 2001/2002 and 2002/2003 IWC/SOWER circumpolar cruises, Area V, Antarctica. J Cetacean Res Manag 7:13-20

* Reeve KA, Boebel O, Kanzow T, Strass V, Rohardt G, Fahrbach E (2016) A gridded data set of upper-ocean hydrographic properties in the Weddell Gyre obtained by objective mapping of Argo float measurements. Earth Syst Sci Data 8:15-40

* Rekdahl ML, Dunlop RA, Goldizen AW, Garland EC, Biassoni N, Miller P, Noad MJ (2015) Non-song social call bouts of migrating humpback whales. J Acoust Soc Am 137:3042-3053

Riesch R, Barrett-Lennard LG, Ellis GM, Ford JK, Deecke VB (2012) Cultural traditions and the evolution of reproductive isolation: ecological speciation in killer whales? Biol J Linn Soc 106:1-17 
Risch D, Parks S (2017) Biodiversity assessment and environmental monitoring in freshwater and marine biomes using ecoacoustics. In: Farina A, Gage SH (eds) Ecoacoustics: the ecological role of sounds. John Wiley \& Sons, Oxford, p 145-168

Risch D, Gales NJ, Gedamke J, Kindermann L and others (2014) Mysterious bio-duck sound attributed to the Antarctic minke whale (Balaenoptera bonaerensis). Biol Lett 10:20140175

Roca IT, Van Opzeeland IC (2019) Using acoustic metrics to characterize underwater acoustic biodiversity in the Southern Ocean. Remote Sens Ecol Conserv, doi:10.1002/ rse2.129

Rogers TL (2003) Factors influencing the acoustic behaviour of male phocid seals. Aquat Mamm 29:247-260

Sala OE, Chapin FS III, Armesto JJ, Berlow E and others (2000) Global biodiversity scenarios for the year 2100. Science 287:1770-1774

Santora JA, Reiss CS, Loeb VJ, Veit RR (2010) Spatial association between hotspots of baleen whales and demographic patterns of Antarctic krill Eupahusia superba suggests size-dependent predation. Mar Ecol Prog Ser 405:255-269

Schall E, Van Opzeeland I (2017) Calls produced by Ecotype C killer whales (Orcinus orca) off the Eckström Iceshelf, Antarctica. Aquat Mamm 43:117-126

Siegel V, Loeb V, Gröger J (1998) Krill (Euphausia superba) density, proportional and absolute recruitment and biomass in the Elephant Island region (Antarctic Peninsula) during the period 1997 to 1997. Polar Biol 19:393-398

Siniff DB, Bengtson JL (1977) Observations and hypotheses concerning the interactions among crabeater seals, leopard seals and killer whales. J Mammal 58:414-416

Siniff DB, Stone S (1985) The role of the leopard seal in the tropho-dynamics of the Antarctic marine ecosystem. In: Siegfried WR, Condy PR, Laws RM (eds) Antarctic nutrient cycles and food webs. Springer, Berlin, p 555-560

Širović A, Hildebrand JA, Wiggins SM, McDonald MA, Moore SE, Thiele D (2004) Seasonality of blue and fin whale calls and the influence of sea ice in the Western Antarctic Peninsula. Deep Sea Res II 51:2327-2344

Širović A, Hildebrand JA, Wiggins SM, Thiele D (2009) Blue and fin whale acoustic presence around Antarctica during 2003 and 2004. Mar Mamm Sci 25:125-136

Sorte CJB, Davidson VE, Franklin MC, Benes KM and others (2017) Long-term declines in an intertidal foundation species parallel shifts in community composition. Glob Change Biol 23:341-352

Spiesecke S (2017) Analysis and modeling of RAFOS signal propagation under the Antarctic sea-ice for positioning Argo floats. MSc thesis, Bremen University of Applied Science

Spreen G, Kaleschke L, Heygster G (2008) Sea ice remote sensing using AMSR-E 89-GHz channels. J Geophys Res Oceans 113:C2S03

Sueur J, Farina A (2015) Ecoacoustics: the ecological investigation and interpretation of environmental sound. Biosemiotics 8:493-502

Sueur J, Pavoine S, Hamerlynck O, Duvail S (2008) Rapid acoustic survey for biodiversity appraisal. PLOS ONE 3: e4065

Sueur J, Farina A, Gasc A, Pieretti N, Pavoine S (2014) Acoustic indices for biodiversity assessment and landscape investigation. Acta Acust 100:772-781
Sueur J, Krause B, Farina A (2019) Climate change is breaking Earth's beat. Trends Ecol Evol 34:971-973

* Templeton CN, Zollinger SA, Brumm H (2016) Traffic noise drowns out great tit alarm calls. Curr Biol 26:R1173R1174

Thiele D, Chester ET, Moore SE, Širović A, Hildebrand JA, Friedlaender AS (2004) Seasonal variability in whale encounters in the Western Antarctic Peninsula. Deep Sea Res II 51:2311-2325

* Thomisch K, Boebel O, Zitterbart DP, Samaran F, Van Parijs S, Van Opzeeland I (2015) Effects of subsampling of passive acoustic recordings on acoustic metrics. J Acoust Soc Am 138:267-278

Thomisch K, Boebel O, Clark CW, Hagen W, Spiesecke S, Zitterbart DP, Van Opzeeland I (2016) Spatio-temporal patterns in acoustic presence and distribution of Antarctic blue whales Balaenoptera musculus intermedia in the Weddell Sea. Endang Species Res 30:239-253

Tyack PL, Zimmer WMX, Moretti D, Southall BL and others (2011) Beaked whales respond to simulated and actual navy sonar. PLOS ONE 6:e17009

Van Opzeeland IC (2010) Acoustic ecology of marine mammals in polar oceans. Berichte zur Polar-und Meeresforschung (Reports on Polar and Marine Research) 619. Alfred-Wegener Institute, Helmholtz Centre for Polar and Marine Research (AWI), Bremerhaven

VVan Opzeeland I, Boebel O (2018) Marine soundscape planning: seeking acoustic niches for anthropogenic sound. J Ecoacoustics 2:5GSNT

Van Opzeeland I, Kindermann L, Boebel O, Van Parijs SM (2008) Insights into the acoustic behaviour of polar pinnipeds: current knowledge and emerging techniques of study. In: Weber EA, Krause LH (eds) Animal behaviour: new research. Nova Science Publishers, New York, NY

*Van Opzeeland I, Van Parijs S, Bornemann H, Frickenhaus $\mathrm{S}$ and others (2010) Acoustic ecology of Antarctic pinnipeds. Mar Ecol Prog Ser 414:267-291

Van Opzeeland I, Van Parijs S, Kindermann L, Burkhardt E, Boebel O (2013a) Calling in the cold: pervasive acoustic presence of humpback whales (Megaptera novaeangliae) in Antarctic coastal waters. PLOS ONE 8:e73007

Van Opzeeland IC, Samaran F, Stafford KM, Findlay K, Gedamke J, Harris D, Miller BS (2013b) Towards collective circum-antarctic passive acoustic monitoring: the southern ocean hydrophone network (SOHN). Polarforschung 83:47-61

Van Parijs S (2003) Aquatic mating in pinnipeds - a review. Aquat Mamm 29:214-226

Van Parijs SM, Clark CW, Sousa-Lima RS, Parks SE, Rankin S, Risch D, Van Opzeeland IC (2009) Management and research applications of real-time and archival passive acoustic sensors over varying temporal and spatial scales. Mar Ecol Prog Ser 395:21-36

V Veech JA (2013) A probabilistic model for analysing species co-occurrence. Glob Ecol Biogeogr 22:252-260

Wendler G, Gilmore D, Curtis J (1997) On the formation of coastal polynyas in the area of Commonwealth Bay, Eastern Antarctica. Atmos Res 45:55-75

*Williams R, Kelly N, Boebel O, Friedlaender AS and others (2015) Counting whales in a challenging, changing environment. Sci Rep 4:4170

Worm B, Barbier EB, Beaumont N, Duffy JE and others (2006) Impacts of biodiversity loss on ocean ecosystem services. Science 314:787-790 


\section{Appendix.}

Text A1. Subsampling analysis. The effects of subsampling were evaluated for a subset of 15 d (every other day between 1 and 29 September 2013) of simultaneously collected passive acoustic recordings from 2 devices. Recordings were collected with a Sonovault (SV, sample rate $5.33 \mathrm{kHz}$; hydrophone sensitivity -193 dB re $1 \mathrm{~V} / \mu \mathrm{Pa}$ ) and an Aural (AU, see Table 1) recorder, which were attached to the same mooring $\left(61^{\circ} 0.88^{\prime} \mathrm{S}, 55^{\circ} 58.53^{\prime} \mathrm{W}\right)$ at virtually the same depth (SV $\left.212 \mathrm{~m}, \mathrm{AU} 210 \mathrm{~m}\right), \mathrm{both}$ recording during the same period. Daily presence detection data of species were obtained by manual perusal of the acoustic data using Raven Pro 1.5 (Bioacoustics Research Program 2019). Acoustic presence information was compared for 8 species (Antarctic blue whale, fin whale, humpback whale, Antarctic minke whale, killer whale, leopard seal, crabeater seal and Ross seal) between both devices on a daily basis and showed $100 \%$ similarity for Antarctic blue, fin, Antarctic minke whales and Ross seals between recorders. For humpback and killer whales, the subsampled AU data missed some events resulting in $89 \%$ and $92 \%$ accordance, respectively, between both data sets. For leopard and crabeater seals, the AU also recorded fewer events than the continuous SV, and accordance was $77 \%$ for leopard seals and $83 \%$ for crabeater seals.

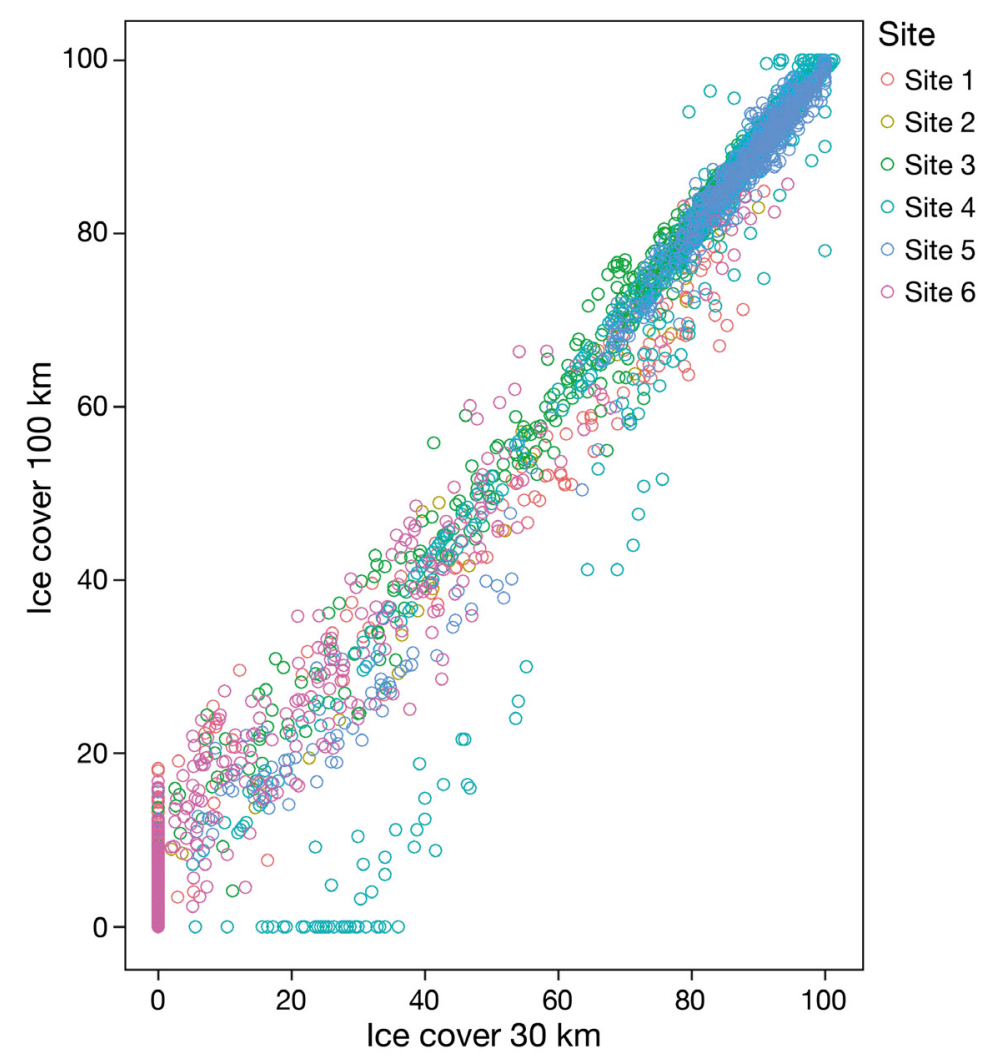

Fig. A1. Correlation scatterplot showing the relationship between sea-ice cover for 30 and $100 \mathrm{~km}$ radii around the recorder position for the 6 different sites 